\title{
A study of combined evaluation of suppliers based on correlation
}

\author{
Heting Qiu, Xuemei Li, Xuewei Li \\ Beïing Jiaotong University (China) \\ kitty9ht@163.com;xmli@,bjtu.edu.cn
}

Received August 2012

Accepted February 2013

\section{Abstract:}

Purpose: The Selection of logistics service providers is an important issue in supply chain management. But different evaluation methods may lead to different results, which could cause inconsistent conclusions. This paper makes use of a new perspective to combine with a variety of methods to eliminate the deviation of different single evaluation methods.

Design/methodology/approach: This paper expounds the application of the combined evaluation method based on correlation. Entropy method, factor analysis, grey colligation evaluation and AHP have been used for research.

Findings: According to the evaluate result, the ranking of suppliers obtained by each method have obvious differences. The result shows that combined evaluation method can eliminate the deviation of different single evaluation methods.

Originality/value: The combined evaluation method makes up for the defects of single evaluation methods and obtains a result that is more stable and creditable with smaller deviation. This study can provide the enterprise leaders with more scientific method to select their cooperative companies.

Keywords: logistics service provider, selection, combined evaluation 


\section{Introduction}

With the development of socialized production, the social division of labor is increasingly elaborate and the specialization degree is becoming higher and higher. As a result, the supply chain system is more important in the productive process. Enterprises have already realized their suppliers have more significant impact on their own development. The evaluation and selection of strategic suppliers as well as establishing a good cooperation relationship with them can completely enhance a company's competition ability in responding to the customers' demands, key technologies, manufacturing costs and customer services, etc. But how to choose the best cooperative partner is really a big problem for the leader of enterprises. In contemporary supply chain management, the performance of suppliers is evaluated against multiple criteria rather than considering a single factor. Quality, price, flexibility, lead time, prompt delivery, batch and other relevant factors are all considered as key factors in evaluating suppliers. Meanwhile, balance their respective weights are very important. So, choosing the most suitable evaluation method is of crucial and imperative significance. Nevertheless, kinds of methods are available as the mature of supplier evaluation system. Giving what we know, we can draw this conclusion, using proper method to choose partner, under this circumstance, is very necessary. But different evaluation methods may lead to different results, which could cause inconsistent conclusions. And it will bring trouble to the decision makers. Therefore, it's important to come up with an idea from a new perspective to eliminate the deviation of different single evaluation methods. The overall objective of the supplier evaluation process is to reduce the risks and offer support to the purchaser.

\section{Literature Review}

Evaluation and selection problem of supplier has been studied extensively. The evaluation of logistics service providers is extremely important to enterprise management. Worldwide scholars have published various evaluation methods and theories. In order to solve the problem of evaluation diversity, the combined evaluation models were proposed. Combined evaluation methods will improve the utilization of suppliers' scores and reduce the random errors and system deviation in the evaluation process. It will make the results of evaluation more scientific and reliable.

From the scientometric perspective, the study of combined evaluation is in the initial stage. Most studies on combined evaluation are focus on the hybrids of two or three approaches, such as the analytic hierarchy process (AHP), analytic network process (ANP), case-based reasoning (CBR), data envelopment analysis (DEA), fuzzy set theory, genetic algorithm (GA), mathematical programming, simple multi-attribute rating technique (SMART), etc. Few studies have been done abroad, which mainly focus on analyzing the reasons of evaluation diversity and how to determine the deviation of single evaluation method using computer simulation 
technologies (Ager, 1977; Natalie \& James, 2002). Theories of Ager and Natalie and James are representative.

In China, Guo (1995) proposed a primary combined evaluation method, providing a solution to evaluation diversity. Based on the study of Zeng (1997) strengthen the method by using a statistical test method. Peng (1995) proposed "attribute weighting method" which is based on multiple methods to assign weights for attributes and then created an optimal model. Qin (2003) constructed an optimization framework based on compatibility and diversity factor. Chen, Chen and Li (2005) studied the combined evaluation method based on game theory. Guo and Yi (2006) put forward an objective combined evaluation method based on evaluation diversity and discrepancy. Su and Chen (2006) extended the theory of using different evaluation methods to combine different levels or subsystems in the evaluation system. Scholars also proposed the generalized evaluation theory based on the integration of various evaluation theories. Li (2007) proposed the frame of the combined evaluation method based on consistency index maximization model. Wang, Yang and $\mathrm{Hu}$ (2008) applied mapping to compose the model of combined evaluation and deal with nonlinear optimization problems by accelerating genetic algorithm (AGA). Jin, Wei and Zhou (2008) generalized the necessary steps in the combined evaluation of complex system and constructed the frame of the combined evaluation of complex system in the view of methodology. Even though people pay more attention to results of single evaluation methods, there are still a few complete researches on the combined evaluation of logistics service providers. Therefore, combining various evaluation methods to avoid evaluation diversity is necessary for the managers to choose the most suitable partners. Meanwhile, both combining evaluation methods and avoiding evaluation diversity are worth studying and urgent to be solved.

In summary, combined evaluation will play a more important role in evaluation field. Till now, although there are many researches, a scientific combined evaluation system has not been established yet. There are fewer achievements in the supplier evaluation field. Besides, there is much space for further study on the mechanism of different evaluation methods, comparative analysis of attribute, evaluation method and object matching, combined evaluation models and combined evaluation theoretical system, etc.

\section{Combined Evaluation Model Based on Correlation}

In statistical methods, correlation is a method of studying the relationships between variables and presenting them with statistical indicators. This paper presents the research of combined evaluation model from the view of correlation indicators. The detailed steps are as follows:

Step 1. Define $\mathrm{N}$ as feasible method set

Step 2. Evaluate the objects by different methods in $\mathrm{N}$ 
Step 3. Construct combined evaluation model

Step $4 . \quad$ Normalize the results of evaluation

Step 5. Calculate each correlation coefficient and its average

Step 6. Calculate the extreme value of correlation coefficient and each weigh value

Step 7. Obtain the result of combined evaluation

Assuming the number of research objects is $\mathrm{N}$ and the number of single evaluation methods is m.

$X_{i}$ - The result of the research object $\mathrm{t}$ by using evaluation method $\mathrm{i}$,

$$
\left\{X_{i t}, \mathrm{i}=1,2, \cdots, \mathrm{m} ; \mathrm{t}=1,2, \cdots, \mathrm{N}\right\}
$$

$\mathrm{P}$ - The result of combined evaluation model based on correlation

$W_{i}$ - The weight of single evaluation method $\mathrm{i}$

$r_{i}$ - The correlation coefficient of $\mathrm{P}$ and $x_{i}$

The model is constructed based on correlation as:

$$
\begin{gathered}
P=\sum_{i=1}^{m} \text { wixi } \\
r_{i}=\frac{\sum x_{i} P-\frac{\sum x_{i} \sum P}{N}}{\sqrt{\left[\sum x_{i}{ }^{2}-\left(\sum x_{i}\right)^{2} / N\right]\left[\sum P^{2}-\left(\sum P\right)^{2} / N\right]}}
\end{gathered}
$$

Calculate the average of $r_{i}$ :

$$
\bar{r}_{i}=\frac{1}{i} \sum\left|r_{i}\right|
$$

Then, put (1) into (3), and get an equation of $W_{i}$ :

$$
\bar{r}_{i}=\frac{1}{i} \sum\left|\frac{\sum x_{i} \sum_{i=1}^{m} w i x i-\frac{\sum x_{i} \sum \sum_{i=1}^{m} w_{i} x_{i}}{N}}{\sqrt{\left[\sum x_{i}{ }^{2}-\left(\sum x_{i}\right)^{2} / N\right]\left[\sum\left(\sum_{i=1}^{m} w i x i\right)^{2}-\left(\sum \sum_{i=1}^{m} w i x i\right)^{2} / N\right]}}\right|
$$


When the average of $r_{i}$ gets the maximum, it means that the result of combined evaluation model $\mathrm{P}$ has the great compatible degree with other results of single evaluation methods. Through the equation below, it can get the value of $W_{i}$.

The target function is: Max $\overline{r i}$

The constraint condition is: $\sum w i=1 ; \quad 0 \leq W_{i} \leq 1$.

After Calculating Wi, substitute the value in equation (1) to calculate the result of combined evaluation model based on correlation.

\section{Application}

This paper evaluates 10 suppliers of an enterprise. At First, a supplier evaluation index system is built. An effective supplier evaluation index system should have certain characteristics such as comprehensiveness, objectiveness, reliability, flexibility and finally, it has to be mathematically straightforward. Through the literature analysis and field investigations, we select 5 kinds of index, including manufacturing capability, technical capability, quality control, service capability and financial index. Then, based on the five kinds of index, several influence factors which can reflect the index are selected. Supplier evaluation index system is shown below:

\begin{tabular}{|l|l|l|}
\hline First level & \multicolumn{2}{l|}{ Second level } \\
\hline \multirow{2}{*}{$\begin{array}{c}\text { manufacturing } \\
\text { capability }\end{array}$} & manufacturing capability & working condition \\
\hline technical capability & standardization operation & safety management \\
\cline { 2 - 3 } & engineering support & design capability \\
\hline \multirow{2}{*}{ quality control } & quality system & spot control \\
\hline & purchase control & quality tools \\
\hline service capability & after-sales service & logistics service \\
\cline { 2 - 3 } & Personnel service & delivery control \\
\hline Financial index & company ownership & payment system \\
\cline { 2 - 3 } & cost control & financial control \\
\hline
\end{tabular}

Table 1. Supplier Evaluation Index System

Relevant data of ten suppliers is obtained by investigation to an enterprise, as shown in Table 1 attached. Then we calculate the results by using entropy method, factor analysis, grey colligation evaluation and AHP. The results of four single evaluation methods are shown in table 2.

From the Table 2, it can be seen that because of the different evaluation views and emphases, different single evaluation methods may lead to different results. So managers often find it 
difficult to decide which solution is more efficient. Since the dimensions of those results are different, they need to be normalized before being combined.

\begin{tabular}{|l|l|l|l|l|}
\cline { 2 - 5 } \multicolumn{1}{c|}{} & Factor Analysis & Gray Correlation & AHP & Entropy \\
\hline supplier1 & 0.9921 & 0.6968 & 0.3119 & 0.0317 \\
\hline supplier2 & -0.0423 & 0.6678 & 0.1845 & 0.0298 \\
\hline supplier3 & -0.5035 & 0.4392 & 0.0342 & 0.0309 \\
\hline supplier4 & -0.4206 & 0.5555 & 0.0907 & 0.0294 \\
\hline supplier5 & 0.0891 & 0.5976 & 0.1462 & 0.0314 \\
\hline supplier6 & -0.3698 & 0.5281 & 0.1131 & 0.0296 \\
\hline supplier7 & 0.1536 & 0.6053 & 0.1595 & 0.0304 \\
\hline supplier8 & 0.0203 & 0.6459 & 0.1862 & 0.0306 \\
\hline supplier9 & -0.2182 & 0.5547 & 0.1384 & 0.0305 \\
\hline supplier10 & 0.2992 & 0.5925 & 0.2156 & 0.0294 \\
\hline
\end{tabular}

Table 2. Single Evaluation Results of Suppliers

This paper makes use of $\left(x_{i}-\min x_{i}\right) /\left(\max x_{i}-\min x_{i}\right) * 100$ to change the results into numbers between 0 and 100 .

The target function is: $\operatorname{Max}=(r 1+r 2+r 3+r 4) / 4$

The constraint conditions are:

$$
\begin{gathered}
\text { St. } w_{1}+w_{2}+w_{3}+w_{4}=1 \\
w_{1}>=0 ; w_{1}<=1 ; \quad w_{2}>=0 ; w_{2}<=1 ; \quad w_{3}>=0 ; w_{3}<=1 ; \quad w_{4}>=0 ; w_{4}<=1 ;
\end{gathered}
$$

Use LINGO to obtain the weigh value at a maximum point of the objective function:

$$
w_{1}=0 ; \quad w_{2}=0.8645 \quad ; w_{3}=0 ; \quad w_{4}=0.1354 ;
$$

Substitute the results in equation (1) and get the result of combined evaluation. Six results of different evaluation methods are shown below:

\begin{tabular}{|c|l|l|l|l|l|l|}
\hline $\begin{array}{c}\text { supplier } \\
\text { sorting }\end{array}$ & Factor Analysis & $\begin{array}{c}\text { Gray } \\
\text { Correlation }\end{array}$ & AHP & Entropy & Average & $\begin{array}{l}\text { Combined } \\
\text { based on } \\
\text { correlation }\end{array}$ \\
\hline 1 & supplier1 & supplier1 & supplier1 & supplier1 & supplier1 & supplier1 \\
\hline 2 & supplier10 & supplier2 & supplier10 & supplier5 & supplier5 & supplier10 \\
\hline 3 & supplier7 & supplier8 & supplier8 & supplier3 & supplier8 & supplier8 \\
\hline 4 & supplier5 & supplier7 & supplier2 & supplier8 & supplier7 & supplier2 \\
\hline 5 & supplier8 & supplier5 & supplier7 & supplier9 & supplier10 & supplier5 \\
\hline 6 & supplier2 & supplier10 & supplier5 & supplier7 & supplier2 & supplier7 \\
\hline 7 & supplier9 & supplier4 & supplier9 & supplier2 & supplier9 & supplier9 \\
\hline 8 & supplier6 & supplier9 & supplier6 & supplier6 & supplier6 & supplier6 \\
\hline 9 & supplier4 & supplier6 & supplier4 & supplier10 & supplier4 & supplier4 \\
\hline 10 & supplier3 & supplier3 & supplier3 & supplier4 & supplier3 & supplier3 \\
\hline
\end{tabular}

Table 3. Contrast of Supplier evaluation results 
From the Table 3, it can be seen that there are obvious differences among different single evaluation methods. Combining these methods based on correlation can create a more compatible result.

\section{Longitudinal comparison}

This case shows that the result of combined evaluation based on correlation is similar with the result of average method. The similarity of the first three suppliers' rankings is $67 \%$, while the last three is almost $100 \%$. We classify the suppliers into three grades: A grade for the top three, $\mathrm{B}$ grade for the middle ones and $\mathrm{C}$ grade for the last three. The grades of both combined evaluation method and average method are almost the same.

According to the raw data, it can be seen that the A grade suppliers have something in common, as each supplier at least has a high-mark influence factor of each first level index. It shows that the comprehensive-developed suppliers have more advantages. Therefore, the suppliers should develop themselves in various aspects so that they would have outstanding performance among suppliers appraisal.

\section{Horizontal comparison}

From table 3, we can obviously find that the result of entropy method has the biggest difference from other results of the evaluation methods. In other evaluation methods, no. 5 supplier is ranking medium. However, the difference of ranking fully reflects the characteristics of the entropy method, that is, if the data just has a little fluctuation, the factors account for the large weight. As suppliers usually getting 35 to 40 points on "software development" index, and the No. 5 supplier getting 70 points, getting high scores on the index of larger weight will affect the ranking of suppliers. Nevertheless, analyzing No.5 supplier's ability in various aspects, we find that the supplier's ability is not good enough in other aspects, and not qualified for the second place. Therefore, Combined Evaluation Based on Correlation is able to eliminate the deviation caused by single evaluation methods. It also can combine the characteristics of various evaluation methods, and concludes the most scientific results.

Overall, therefore, the result of combined evaluation method is very scientific and creditable. So it's valuable for decision-making.

\section{Conclusion}

From different perspective, different single supplier evaluation methods may lead to different results. However, they all have some deficiency. The combined evaluation method makes up for the defects of single evaluation methods and obtains a result that is more stable and creditable with smaller deviation. This study shows that the combined evaluation based on 
correlation is reasonable and provides the managers more scientific method to select their cooperative companies.

\section{Acknowledgments}

This paper was supported by "Special Foundation of Beijing Municipal Education Commission Joint Project", the project is "Theory and Practice of Beijing Logistics Value Extension Network Based on the Comprehensive Transportation".

\section{References}

Ager, R.R. (1977). Multiple objective decision-making based on fuzzy sets. International Journal of Man-Machine Studies.

Chen, Y., Chen, G., \& Li, M. (2005). Research on Determining Weights of Combination Evaluation Method Using Cooperative Games, Chinese Journal of Management Science.

Guo, X. (1995). A new comprehensive evaluation method - combined evaluation, Statistical Research.

Guo, Y., \& Yi, P. (2006). Whole Diversity-Based Reasoning for Objective Combined Evaluation, Chinese Journal of Management Science.

Jin, J., Wei, Y., \& Zhou, Y. (2008). Theoretical Frame of Comprehensive Evaluation of Complex System and Its Application to Evaluating Water Security, System Sciences and Comprehensive Studies in Agriculture.

Li, W. (2007). Research on Theory and Methodology of the Evaluation of Enterprise's Competitiveness, doctoral dissertation, Beijing Jiaotong University.

Natalie, M., \& James, R. (2002). An Improved Batch Means Procedure for Simulation Output Analysis, Management Science, 48(12), 1569-1586. http://dx.doi.org/10.1287/mnsc.48.12.1569.438

Peng, Y. (1995). Combination Evaluation Research of International Investment Environment, Systems Engineering - Theory \& Practice.

Qin, S. (2003). Comprehensive evaluation Principle and Application. Electronic Industry Press.

Su, W., \& Chen, J. (2006). Some Considerations to Extend Comprehensive Evaluation Technique, Statistical Research.

Wang, S., Yang, S., \& Hu, X. (2008). Combinational evaluation method based on projection pursuit algorithm, Engineering Sciences. 
Zeng, X. (1997). Priori and Post Tests of Combination Evaluation, Statistical Research.

Journal of Industrial Engineering and Management, 2013 (www.jiem.org)

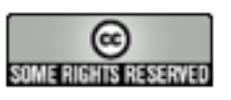

El artículo está con Reconocimiento-NoComercial 3.0 de Creative Commons. Puede copiarlo, distribuirlo y comunicarlo públicamente siempre que cite a su autor y a Intangible Capital. No lo utilice para fines comerciales. La licencia completa se puede consultar en http://creativecommons.org/licenses/by-nc/3.0/es/ 